\title{
Implementasi Hukum Pasal 35 Undang-Undang Nomor 39 Tahun 2004 dalam Program Recognised Seasonal Employment
}

\author{
Lukas Banu1
}

${ }^{1}$ Institute of Justice Law Firm, Badung, E-mail: luc_chry@yahoo.com

\begin{abstract}
Info Artikel
Masuk : 3 April 2018

Diterima : 26 Mei 2018

Terbit : 28 Mei 2018

Keywords :

Indonesian workers, Human

Rights, education

Kata kunci:

Tenaga Kerja Indonesia,

Hak Asasi Manusia,

pendidikan

Corresponding Author:

Lukas Banu, E-mail:

luc_chry@yahoo.com

DOI :

10.24843/JMHU.2018.v07.i01. p08
\end{abstract}

\section{Abstract}

Indonesia regulations are ensuring that work as the human right for all people and therefore the state is expected to protect it. The workers have same right and opportunity without discrimination to create the income for them and their families. One of the real action of the government in protecting the workers is making and applying the Act Number 39/2004 on Placement and Protection of Indonesian Workers. The purpose of this research is to know how Article 35 of Act Number 39/2004 would be implemented in particular for Indonesian workers who work under Recognised Seasonal Employment New Zealand scheme. The research is very important to be done to find the difference between the regulation which made by Indonesian government on a category of minimum education that determined by law for the candidate of Indonesian workers and the implementation of that regulation. The researcher is using normative legal research with statute approach and fact approach. The fact approach is adjusted with the process of recruitment, sending and placement of Indonesian workers in New Zealand. The result of research is showing that even though the Article 35 of Act Number 39/2004 requires the Junior High School as the minimum education but in reality, the Indonesian workers who work under RSE New Zealand scheme are not in accordance with it where some of them only have Elementary School background.
\end{abstract}

\begin{tabular}{l}
\hline Abstrak \\
\hline Peraturan perundang-undangan di Indonesia menjamin \\
bahwa bekerja merupakan hak asasi setiap manusia dan \\
oleh karena itu maka negara diharapkan hadir untuk \\
memastikan hak tersebut dijamin dan dilindungi. Setiap \\
tenaga kerja memiliki hak dan kesempatan yang sama \\
tanpa adanya diskriminasi agar dapat memperoleh \\
penghasilan yang layak yang akan digunakan untuk \\
pekerja serta keluarganya. Bentuk nyata yang dilakukan \\
oleh negara terhadap tenaga kerja Indonesia adalah \\
dengan adanya Undang-Undang Nomor 39 Tahun 2004 \\
Tentang Penempatan dan Perlindungan Tenaga Kerja \\
Indonesia. Penelitian ini bertujuan untuk mengetahui \\
bagaimana implementasi hukum Pasal 35 UU No.39 Tahun \\
2004 khususnya bagi TKI yang bekerja dibawah program \\
Recognised Seasonal Employment New Zealand. Penelitian ini \\
sangat penting dilakukan untuk menemukan perbedaan
\end{tabular}


antara aturan yang dibuat oleh pemerintah tentang kategori pendidikan minimum yang ditentukan dalam Undang-Undang bagi calon TKI dengan penerapan di lapangan. Jenis penelitian yang dilakukan adalah penelitian hukum normatif dengan pendekatan perundang-undangan serta pendekatan fakta. Pendekatan fakta di lapangan disesuaikan dengan proses yang terjadi dalam perekrutan yang dilakukan serta pengiriman dan penempatan TKI itu sendiri di negara New Zealand. Hasil yang diperoleh dalam penelitian menunjukkan bahwa meskipun Pasal 35 Undang-Undang Nomor 39 Tahun 2004 mensyaratkan pendidikan menimum SMP bagi calon TKI akan tetapi kenyataannya para TKI yang terlibat dalam program RSE New Zealand tidak sesuai di mana mereka ada juga yang memiliki pendidikan Sekolah Dasar. Fakta ini menunjukkan bahwa meskipun Undang-Undang tersebut terkesan membatasi namun sesungguhnya nilai yang terkandung di dalamnya justru sesuai di mana bekerja merupakan hak asasi manusia yang wajib dijunjung tinggi, dihormati dan di jamin penegakannya.

\section{Pendahuluan}

Bekerja merupakan hak asasi manusia dan oleh karena itu negara diminta berperan aktif untuk memberikan perlindungan bagi warga negaranya. Setiap tenaga kerja memiliki hak dan kesempatan yang sama tanpa adanya diskriminasi baik di dalam negeri maupun di luar negeri. Salah satu kesempatan yang sering dicapai bagi Tenaga Kerja Indonesia (TKI) adalah bekerja di luar negeri yang mayoritas lebih memberikan penghasilan lebih baik dibandingkan dengan di dalam negeri. ${ }^{1}$

Adapun negara-negara yang menjadi tujuan bagi para TKI adalah negara-negara maju yang berpenghasilan tinggi sehingga lebih membuka peluang untuk menciptakan hidup yang lebih layak. ${ }^{2}$ New Zealand yang merupakan salah satu negara maju dengan peringkat ke-203 sebagaimana dirilis oleh Bank Dunia pada tahun 2013 menjadi negara yang dituju oleh TKI. Kesempatan bagi TKI untuk bekerja di New Zealand menjadi terbuka dengan adanya program Recognised Seasonal Employment (RSE).

RSE adalah program yang diperuntukkan bagi perusahaan-perusahaan di New Zealand yang bergerak di sektor industri buah kiwi, anggur dan apel. Direct Management Services Pro Growers (DMS) merupakan salah satu perusahaan yang bergerak di sektor industri buah kiwi yang sejak tahun 2007 sampai saat ini telah merekrut TKI setiap tahun. TKI tersebut dipekerjakan setiap 6 bulan dalam setahun

\footnotetext{
${ }^{1}$ Rumbadi, R. (2017). Peran Dan Tanggungjawab Kementerian Luar Negeri Melindungi Wni Dan Tki Di Luar Negeri. Jurnal Dimensi. 6(2). h. 7.

2 Santoso, I. (2014). Diaspora, Globalisme, Keamanan dan Keimigrasian. Bandung. Pustaka Reka Cipta. h. 105.

${ }^{3}$ Ibid.
} 
untuk ditempatkan di dalam pack house dan juga di area perkebunan agar roda ekonomi di sektor tersebut tetap berjalan. ${ }^{4}$

Jenis pekerjaan yang diberikan pada TKI adalah grader (pemilih buah), tray prep (penyuplai kotak kemasan), packer (pengepak buah kiwi) dan stacker (penyusun kotak berisi buah). Proses pengiriman dan penempatan TKI dalam program RSE sangat kompleks namun kebijakan ini cukup beralasan untuk dibuat guna menghindari terjadinya persoalan yang berpotensi muncul di kemudian hari sebagaimana yang banyak dialami oleh TKI yang bekerja di sektor non formal. Kebijakan tersebut dibuat oleh pemerintah yang kemudian dituangkan dalam peraturan perundang-undangan seperti Undang-Undang Nomor 39 Tahun 2004 tentang Penempatan dan Perlindungan Tenaga Kerja Indonesia serta peraturan pelaksana lainnya.

Pasal 35 UU No.39/2004 menentukan syarat bagi calon TKI antara lain:

a. Berusia sekurang-kurangnya 18 tahun;

b. Sehat jasmani dan rohani;

c. Tidak dalam keadaan hamil bagi calon TKI perempuan;

d. Berpendidikan sekurang-kurangnya lulus Sekolah Lanjutan Tingkat Pertama (SLTP).

Ketentuan di atas seharusnya menjadi panduan bagi calon TKI dan juga setiap pihak yang terlibat dalam proses pengiriman TKI ke luar negeri di mana setiap TKI wajib memenuhi syarat-syarat tersebut. Salah satu syarat tersebut adalah mengenai latar belakang pendidikan yang ditentukan minimum lulus SLTP.

Program RSE sendiri tidak mensyaratkan pendidikan minimum melainkan lebih kepada kapasitas tenaga kerja dalam melakukan pekerjaan di mana kunci penting terletak kepada kesehatan tenaga kerja serta etika bekerja. ${ }^{5}$ Kualifikasi tenaga kerja tertuang di dalam surat job offer atau letter of offer yang memuat jumlah TKI yang diperlukan, jenis pekerjaan, kualifikasi TKI, syarat-syarat kerja, jaminan sosial dan masa berlaku. ${ }^{6}$ Job of offer dalam program RSE tidak menyebutkan secara pasti tentang syarat minimum pendidikan bagi calon TKI.

Penulisan ini bertujuan untuk mengetahui implementasi hukum Pasal 35 UndangUndang Nomor 39 Tahun 2004 tentang Penempatan dan Perlindungan Tenaga Kerja Indonesia dalam Program Recognised Seasonal Employment New Zealand.

\section{Metode Penelitian}

Jenis penelitian yang digunakan dalam penelitian ini adalah penelitian hukum normatif. Penelitian normatif dilakukan berdasarkan data sekunder atau kepustakaan. Meskipun demikian, penelitian ini juga didukung oleh data yang diperoleh melalui wawancara terhadap pihak-pihak yang memiliki ilmu dan pengetahuan yang

${ }^{4}$ Anggriani, R. (2017). Perlindungan Hukum Bagi Irregular Migrant Workers Indonesia Di Kawasan Asia Tenggara (Dalam Perspektif Hukum Ham Internasional). Yuridika, 32(2), 310335, h. 3.

5 Trisnawati, D., Astuti, P., \& Astrika, L. (2015). Peran Pemerintah dalam Memberikan Perlindungan terhadap Tenaga Kerja Indonesia yang Bekerja di Luar Negeri (Studi pada Dinas Tenaga Kerja dan Transmigrasi Provinsi Jawa Tengah). Journal of Politic and Government Studies, 4(2), 131-145, h. 6.

${ }^{6}$ Abdussalam, H. R. \& Adri Desasfuryanto. (2015). Hukum Ketenagakerjaan (Hukum Perburuhan). Jakarta. PTIK. h. 287. 
berkaitan dengan topik yang diangkat. Selain itu, penggalian informasi juga dilakukan melalui pengamatan secara langsung tentang proses perekrutan calon TKI sampai dengan penempatan TKI tersebut di perusahaan DMS New Zealand yang mana hal tersebut dilakukan langsung pada tangal 26 - 28 Mei 2017 di DMS New Zealand.

\section{Hasil dan Pembahasan}

\subsection{Persyaratan minimum pendidikan bagi calon Tenaga Kerja Indonesia menurut Pasal 35 Undang-Undang Nomor 39 Tahun 2004 tentang Penempatan dan Perlindungan Tenaga Kerja Indonesia}

Pasal 32 ayat (1) Undang-Undang Nomor 13 Tahun 2003 tentang Ketenagakerjaan menguraikan asas-asas yang menjiwai penempatan tenaga kerja yaitu; terbuka, bebas, obyektif serta adil dan setara tanpa diskriminasi. ${ }^{7}$ Prinsip yang sama juga terlihat dalam UU No.39 Tahun 2004 di mana setiap tenaga kerja memiliki kesempatan yang sama tanpa diskriminasi untuk memperoleh pekerjaan dan penghasilan yang layak. Negara dalam hal ini berperan sebagai penjamin dan pelindung hak asasi warga negaranya baik mereka yang bekerja di dalam negeri maupun di luar negeri.

Persoalan perdagangan manusia, perbudakan, kerja paksa, korban kekerasan merupakan kejadian yang cukup sering dialami oleh TKI di mana persoalan tersebut banyak ditimbulkan dari sektor pekerjaan sebagai pembantu rumah tangga. ${ }^{8}$ Oleh karena itu pemerintah Indonesia menaruh perhatian khusus pada sektor tersebut agar persoalan terkait tidak muncul lagi atau setidaknya dapat diantisipasi dan diminimalisir. Tindakan aktif pemerintah dapat dilihat melalui perangkat peraturan yang dibuat dan diberlakukan serta membentuk institusi yang berfungsi sebagai pengawas serta memberikan perlindungan bagi para TKI khususnya bagi anak-anak yang harus memperoleh keadilan. ${ }^{9}$

Pasal 35 UU No.39 Tahun 2004 mensyaratkan minimal berusia 18 tahun serta memiliki pendidikan minimum bagi para calon TKI yaitu Sekolah Lanjutan Tingkat Pertama (SLTP). Indikator ini ditentukan sebagai pertimbangan di mana TKI diharapkan betulbetul matang dalam aspek kepribadian dan emosi. Walau demikian, dalam prakteknya di Indonesia banyak terdapat pekerja anak di bawah umur yang kebanyakan merupakan akibat dari faktor kemiskinan dan kondisi ekonomi. ${ }^{10}$

Hukum Perdata Indonesia juga menentukan suatu batasan usia seseorang untuk dianggap cakap bertindak secara hukum yaitu 18 (delapan belas) tahun. Seseorang yang berumur 18 tahun dianggap telah mampu mempertanggungawabkan tindakannya. Latar belakang pendidikan yang dimiliki oleh seseorang juga menentukan kemampuannya dalam berpikir dan bertindak sesuai dengan informasi dan pengetahuan yang diperolehnya.

\footnotetext{
${ }^{7}$ Khakim, A. (2014). Dasar-Dasar Hukum Ketenagakerjaan Indonesia. Bandung. Citra Aditya Bakti. h. 19-20.

8 Nuraeny, H. (2018). Pengiriman Tenaga Kerja Migran Sebagai Salah Satu Bentuk Perbudakan Modern Dari Tindak Pidana Perdagangan Orang. Jurnal Hukum dan Peradilan, 4(3). 501-518.

${ }^{9}$ Wicaksono, D.\&Hartanto. (2018). Perlindungan Hak Asasi Anak di Bawah Umur sebagai Korban Tindak Pidana Kesusilaan di Wilayah Hukum Polres Boyolali. Disertasi. Surakarta. Universitas Muhammadiyah. h. 9.

10 Putri, S. A., \& Takariawan, A. (2018). Pemahaman Mengenai Perlindung Korban Perdagangan Anak (Trafficking) Dan Pekerja Anak Di Bawah Umur Di Jawa Barat. Dharmakarya. 6(4). h. 1.
} 
Aswanto mengelompokkan Hak Asasi Manusia (HAM) menjadi 4 (empat) bagian dan hak untuk bekerja merupakan salah satu bagian dari hak sosial ekonomi. ${ }^{11}$ Negara berkewajiban untuk memastikan bahwa setiap penduduknya memperoleh haknya masing-masing berdasarkan prinsip dan nilai keadilan. Tugas tersebut tertuang dalam Pasal 27 ayat (2) UUD 1945 yang menyatakan bahwa "Tiap-tiap warga negara berhak atas pekerjaan dan penghidupan yang layak bagi kemanusiaan."

Negara Indonesia memiliki cita-cita yang mulia yaitu memajukan kesejahteraan umum bagi warga negaranya. ${ }^{12}$ Hak atas pekerjaan sebagaimana disebutkan di atas bertujuan untuk menciptakan penghidupan yang layak baik bagi tenaga kerja itu sendiri maupun keluarganya. Dengan adanya globalisasi maka setiap orang memiliki kesempatan untuk memilih tempat di mana mereka bekerja baik di dalam negeri maupun di luar negeri.

Upaya pemerintah dalam rangka mencerdaskan kehidupan bangsa sebagaimana dituangkan dalam bagian pembukaan konstitusi Negara Indonesia sejalan dengan tuntutan situasi dan keadaan di era globalisasi. Pemerintah mengharapkan agar angkatan kerja Indonesia mampu bersaing dengan angkatan kerja dari negara lainnya dan tetap memperoleh hak-hak mereka sesuai dengan harkat dan martabatnya. ${ }^{13}$ Penentuan SLTP sebagai pendidikan minimum bagi calon TKI yang akan bekerja di luar negeri didasarkan pada latar belakang di atas.

Tenaga kerja merupakan salah satu bagian modal dan oleh karena itu proses pembentukannya mesti dilakukan dengan komprehensif. Setiap elemen pemerintah wajib berupaya untuk memperoleh dan meningkatkan jumlah penduduk yang mempunyai keahlian, pendidikan dan pengalaman yang menentukan bagi pembangunan ekonomi Indonesia. ${ }^{14}$ Pemerintah sangat sadar bahwa persoalan pengangguran harus diatasi dengan cara yang sistematis dan berkelanjutan karena dari isu ini dapat menimbulkan persoalan-persoalan di berbagai aspek kehidupan seperti ekonomi dan hukum.

Harapan pemerintah berkaitan dengan sektor sumber daya manusia yang nantinya akan bekerja di luar negeri adalah mendorong TKI agar dapat mengalami peningkatan pendidikan dan keterampilan. Pemerintah percaya bahwa dengan meningkatnya kualitas pendidikan dan keterampilan serta kompetensi maka kesempatan bagi TKI pun untuk memperoleh pekerjaan di luar negeri juga semakin terbuka. ${ }^{15}$ Pada akhirnya tujuan TKI untuk mewujudkan kesejahteraan bagi dirinya dan keluarganya dapat tercapai.

${ }^{11}$ Qamar, N. (2013). Hak Asasi Manusia Dalam Negara Hukum Demokrasi (Human Rights in Democratiche Rechtsstaat). Jakarta. Sinar Grafika. h. 96-98.

12 Soemarsono, M. (2017). Negara Hukum Indonesia Ditinjau Dari Sudut Teori Tujuan Negara. Jurnal Hukum \& Pembangunan. 37(2). 300-322. h. 5.

${ }^{13}$ Husni, L. (2015). Asas Hukum Dalam Undang-undang Nomor 39 Tahun 2004 Untuk Mewujudkan Penempatan Dan Perlindungan Tenaga Kerja Indonesia Yang Bermartabat. Jurnal Media Hukum. 17(1). h.3.

${ }^{14}$ Jhingan, M. L. (2008). Ekonomi Pembangunan Dan Perencanaan. Jakarta. Raja Grafindo Persada. h. 414

${ }^{15}$ Sukomono, A. F. (2017). Perlindungan Tenaga Kerja Indonesia di Luar Negeri Melalui Sertifikasi Kompetensi. Dialogia Iuridica: Jurnal Hukum Bisnis dan Investasi. 8(2). 53-61. 


\subsection{Persyaratan Bagi Calon Tenaga Kerja Indonesia Dalam Program Recognised Seasonal Employment New Zealand.}

Program RSE dimulai dengan adanya letter of offer yang dikeluarkan oleh perusahaan di New Zealand. Salah satu perusahaan tersebut adalah DMS yang telah merekrut TKI sejak tahun 2007 hingga sekarang. Kriteria TKI yang direkrut oleh DMS antara lain:

a. Berusia 25 - 50 tahun;

b. Secara fisik calon TKI sesuai dengan pekerjaan yang diperlukan;

c. Memiliki karakter yang baik;

d. Tidak mengkonsumsi alkohol dan obat-obatan terlarang;

e. Memiliki catatan kelakuan baik;

f. Bersedia bekerja pada malam hari dan di akhir minggu;

g. Bersedia bekerja di pack house atau di kebun atau kombinasi keduanya;

h. Bersedia bekerja selama 6 (enam) bulan;

i. Bersedia mentaati aturan yang ditentukan oleh perusahaan.

Secara umum, letter of offer yang dikeluarkan tersebut tidak mensyaratkan minimum pendidikan yang harus dimiliki oleh calon TKI. Perusahaan DMS lebih memfokuskan pada kemampuan calon TKI dalam bekerja meskipun dalam prakteknya faktor bahasa ${ }^{16}$ menjadi suatu tantangan tersendiri bagi pekerja namun dengan adanya perwakilan pekerja maka isu tersebut dapat teratasi. DMS selalu memberikan pengarahan awal (induction) di awal TKI datang ke New Zealand dan bahkan mereka dibekali dengan pelatihan terlebih dahulu sesuai dengan jenis pekerjaan yang ditentukan bagi mereka.

Latar belakang program RSE tersebut sesungguhnya merupakan program pemerintah New Zealand dalam memberikan bantuan kepada masyarakat yang tinggal di kepulauan pasifik. New Zealand bersama dengan Australia mewujudkan kepedulian mereka terhadap negara-negara tetangga mereka dengan membuka kesempatan bagi pekerja di kepulauan pasifik untuk datang dan bekerja di New Zealand. Melalui program RSE diharapkan terjalin hubungan yang baik dengan masyarakat di mana tenaga kerja tersebut berasal dan juga dapat terjadi alih informasi dan teknologi serta etika bekerja sehingga nantinya pengalaman tersebut dapat diterapkan di lingkungan atau negara pekerja berasal.

Prinsip yang dilakukan oleh DMS melalui program RSE sejalan dengan prinsip yang diakui oleh The United Nations Global Compact. Adapun prinsip yang dimaksud adalah pemahaman bahwa perusahaan atau korporasi harus membangun hubungan dengan masyarakat dan isu hak asasi manusia dalam rangka pengembangan ilmu pengetahuan dan teknologi. ${ }^{17}$ TKI yang ikut dalam program RSE juga diharapkan terjadi perubahan atau proses pemberdayaan baik pribadi, keluarga dan masyarakat.

Implementasi program RSE sejalan dengan teori hukum sebagai sarana perubahan yang dikemukakan oleh Roscoe Pound. Hukum berfungsi sebagai rekayasa masyarakat atau sebagai alat pengontrol masyarakat dan pada akhirnya produk

${ }^{16}$ Bartley, A., Beddoe, L., Duke, J., Fouché, C., Harington, P., \& Shah, R. (2016). Crossing borders: key features of migrant social workers in New Zealand. Aotearoa New Zealand Social Work. 23(3). 16-30.

${ }^{17 K r i s t i a n . ~(2014) . ~ H u k u m ~ K o r p o r a s i ~ D i t i n j a u ~ D a l a m ~ T h e ~ U n i t e d ~ N a t i o n s ~ G l o b a l ~ C o m p a c t ~(S u a t u ~}$ Pengantar). Bandung. Nuansa Aulia. h. 43. 
hukum yang dibuat oleh pemerintah dapat mempengaruhi bahkan mengubah sendisendi kehidupan masyarakat. ${ }^{18}$ Pemerintah diminta untuk membuat kebijakan yang mampu melindungi dan mengayomi masyarakat yang kurang mampu baik dari bidang ekonomi, pendidikan serta kemampuan untuk mengakses kesempatan yang ada.

Sebagian besar TKI yang bekerja dalam program RSE memiliki latar belakang pendidikan yang kurang dari SLTP sebagaimana ditentukan dalam Pasal 35 UU No.39 Tahun 2004. DMS bekerjasama dengan Yayasan Tangan Pertolongan Bali yang memfasilitasi perekrutan bersama dengan PT. Bali Duta Mandiri sebagai perusahaan yang memiliki ijin untuk mengirim TKI ke luar negeri memiliki pemahaman yang sama yaitu untuk memberdayakan masyarakat yang kurang mampu dengan membuka kesempatan bagi mereka juga untuk dapat bekerja di luar negeri. Fakta ini memiliki dua sisi yang saling bertolak belakang di mana di satu sisi program RSE berlawanan dengan ketentuan Pasal 35 UU No.39 Tahun 2004 namun di sisi lain program ini justru merupakan implementasi nyata dari tujuan negara untuk mencerdaskan kehidupan bangsa dan memajukan kesejahteraan umum dan oleh karena itu maka perwakilan Indonesia yang berada di New Zealand berkewajiban untuk memantau dan mengawasi TKI tersebut. ${ }^{19}$

Selain itu, program RSE juga sejalan dengan ketentuan Pasal 27 UUD 1945 di mana negara wajib menjamin hak setiap warga negaranya untuk memperoleh pekerjaan yang layak. Kontradiksi antara ketentuan dan praktek program RSE mesti disikapi secara bijaksana agar negara mampu memberikan kepastian hukum dan juga di pihak lain negara mampu menjamin hak asasi warga negaranya. Roscoe Pound lebih detail menjabarkan bahwa perubahan atas hukum atau sebuah aturan berasal dari berbagai stimulus yang salah satunya adalah adanya kebutuhan dadakan dari masyarakat karena keadaan khusus atau darurat dalam hubungan dengan distribusi sumber daya baik alam maupun manusia atau dalam hubungan dengan standar baru tentang keadilan.

Dalam prakteknya, TKI mampu mengemban tugas yang diberikan oleh perusahaan DMS dengan baik. Hal ini dibuktikan dengan permintaan TKI oleh DMS yang telah berlangsung konsisten selama lebih dari 10 (sepuluh) tahun. Pendidikan minimum yang disyaratkan dalam Pasal 35 UU No.39 Tahun 2004 tidak menjadi halangan bagi TKI untuk bekerja serta tidak menimbulkan persoalan bagi perusahaan DMS yang mempekerjakan TKI.

\section{Kesimpulan}

Ketentuan syarat pendidikan minimum yaitu SLTP bagi calon TKI di dalam Pasal 35 UU No.39 Tahun 2004 dilatarbelakangi oleh pertimbangan pemerintah untuk mengantisipasi terjadinya perdagangan manusia, perbudakan, kerja paksa, korban kekerasan, kesewenang-wenangan, kejahatan atas harkat martabat manusia dan perlakuan lain yang dikategorikan sebagai pelanggaran hak asasi manusia. Pemerintah beranggapan bahwa setiap calon TKI yang telah

${ }^{18}$ Munir Fuady, 2014, Teori-Teori Besar (Grand Theory) Dalam Hukum. Jakarta. Kencana Prenadamedia Group. h. 248-250.

${ }^{19}$ Muin, F. (2015). Perlindungan Hukum Terhadap Tenaga Kerja Indonesia (Tinjauan Terhadap UU Nomor 39 Tahun 2004 Tentang Penempatan dan Perlindungan Tenaga Kerja Indonesia). Jurnal Cita Hukum. 3(1). h. 19. 
mengenyam pendidikan SLTP maka mampu berpikir dewasa, matang dan memiliki emosi yang baik dalam bertindak sehingga dapat menjaga diri mereka selama bekerja di luar negeri.

Program RSE tidak menitikberatkan pada latar belakang pendidikan SLTP bagi calon TKI karena perusahaan lebih menekankan pada etika bekerja serta informasi dan keterampilan yang selalu diberikan kepada TKI di awal bekerja (induction) dalam rangka memperlengkapi TKI. Latar belakang program RSE adalah pemberdayaan bagi masyarakat yang kurang mampu baik aspek ekonomi, pendidikan serta kelemahan dalam mengakses kesempatan. Implementasi ini sejalan dengan cita-cita negara Indonesia untuk mencerdaskan kehidupan bangsa dan memajukan kesejahteraan umum serta bukti nyata negara hadir untuk memberikan jaminan bagi warga negaranya untuk bekerja sebagai salah satu hak asasi manusia.

\section{Daftar Pustaka}

Buku

Khakim, A. (2014). Dasar-Dasar Hukum Ketenagakerjaan Indonesia. Bandung: PT Citra Aditya Bakti

Abdussalam, H. R. \& Desasfuryanto, A. (2015). Hukum Ketenagakerjaan (Hukum Perburuhan). Jakarta: PTIK.

Santoso, I. (2014). Diaspora, Globalisme, Keamanan dan Keimigrasian. Bandung: Pustaka Reka Cipta.

Jhingan, M. L. (2000). Ekonomi pembangunan dan perencanaan.Penerjemah: D. Guritno. Edisi Pertama. Jakarta: PT Raja Grafindo Persada.

Kristian. (2014). Hukum Korporasi Ditinjau Dalam The United Nations Global Compact (Suatu Pengantar). Bandung: Nuansa Aulia.

Fuady, M. (2014). Teori-Teori Besar (Grand Theory) Dalam Hukum. Jakarta: Kencana Prenadamedia Group.

Qamar, N. (2013). Hak Asasi Manusia Dalam Negara Hukum Demokrasi (Human Rights in Democratiche Rechtsstaat). Jakarta: Sinar Grafika.

\section{Jurnal}

Anggriani, R. (2017). Perlindungan Hukum Bagi Irregular Migrant Workers Indonesia Di Kawasan Asia Tenggara (Dalam Perspektif Hukum HAM Internasional). Yuridika. 32(2). 310-335. http://dx.doi.org/10.20473/ydk.v32i2.4773

Bartley, A., Beddoe, L., Duke, J., Fouché, C., Harington, P., \& Shah, R. (2016). Crossing borders: key features of migrant social workers in New Zealand. Aotearoa New Zealand Social Work.23(3). 16-30. http://dx.doi.org/10.11157/anzswjvol23iss3id157

Husni, L. (2015). Asas Hukum Dalam Undang-undang Nomor 39 Tahun 2004 Untuk Mewujudkan Penempatan Dan Perlindungan Tenaga Kerja Indonesia Yang Bermartabat. Jurnal Media Hukum. 17(1). 132-150. 
Muin, F. (2015). Perlindungan Hukum Terhadap Tenaga Kerja Indonesia (Tinjauan Terhadap UU Nomor 39 Tahun 2004 Tentang Penempatan dan Perlindungan Tenaga Kerja Indonesia). Jurnal Cita Hukum.3(1). 11-24. http://dx.doi.org/10.15408/jch.v2i1.1838.

Nuraeny, H. (2018). Pengiriman Tenaga Kerja Migran Sebagai Salah Satu Bentuk Perbudakan Modern Dari Tindak Pidana Perdagangan Orang. Jurnal Hukum dan Peradilan, 4(3), 501-518.

Putri, S. A., \& Takariawan, A. (2018). Pemahaman Mengenai Perlindung Korban Perdagangan Anak (Trafficking) Dan Pekerja Anak Di Bawah Umur Di Jawa Barat. Dharmakarya. 6(4), 245-249.

Rumbadi, R. (2017). Peran Dan Tanggungjawab Kementerian Luar Negeri Melindungi Wni Dan Tki Di Luar Negeri. Jurnal Dimensi. 6(2).

Soemarsono, M. (2017). Negara Hukum Indonesia Ditinjau Dari Sudut Teori Tujuan Negara. Jurnal Hukum $\mathcal{E} \quad$ Pembangunan.37(2). 322. http://dx.doi.org/10.21143/jhp.vol37.no2.1480

Sukomono, A. F. (2017). Perlindungan Tenaga Kerja Indonesia di Luar Negeri Melalui Sertifikasi Kompetensi. Dialogia Iuridica: Jurnal Hukum Bisnis dan Investasi. 8(2). 53-61.

Trisnawati, D., Astuti, P., \& Astrika, L. (2015). Peran Pemerintah dalam Memberikan Perlindungan terhadap Tenaga Kerja Indonesia yang Bekerja di Luar Negeri (Studi pada Dinas Tenaga Kerja dan Transmigrasi Provinsi Jawa Tengah). Journal of Politic and Government Studies. 4(2). 131-145.

\section{$\underline{\text { Disertasi }}$}

Wicaksono, D., Hartanto (2018). Perlindungan Hak Asasi Anak di Bawah Umur sebagai Korban Tindak Pidana Kesusilaan di Wilayah Hukum Polres Boyolali. Disertasi. Surakarta. Universitas Muhammadiyah Surakarta.

\section{Peraturan Perundang-Undangan}

Undang-Undang Dasar Negara Republik Indonesia 1945

Undang-Undang tentang Ketenagakerjaan, Undang-Undang Nomor 13 Tahun 2003, Lembaran Negara Republik Indonesia, Tambahan Lembaran Negara Republik Indonesia No.39

Undang-Undang tentang Penempatan dan Perlindungan Tenaga Kerja Indonesia Di Luar Negeri, Undang-Undang Nomor 39 Tahun 2004, Lembaran Negara Republik Indonesia, Tambahan Lembaran Negara Republik Indonesia No.133 